\title{
Central-ring functionalization and application of the rigid, aromatic, and H-shaped pentiptycene scaffold
}

\author{
Jye-Shane Yang*a and Jyu-Lun Yan ${ }^{b}$ \\ Received (in Cambridge, UK) 31st August 2007, Accepted 22nd November 2007 \\ First published as an Advance Article on the web 14th February 2008 \\ DOI: $10.1039 / b 713428 m$
}

The progress of pentiptycene chemistry is reviewed. Pentiptycene belongs to the iptycene family and possesses a rigid, aromatic, and $\mathrm{H}$-shaped scaffold. An important feature for pentiptycene $v s$. triptycene is the presence of a 'sterically shielded' central benzene ring. Such a feature has led to the use of pentiptycene as a conformational regulator and in the formation of functional molecules, including fluorescent chemosensors, molecular machines, low dielectric constant materials, and porous solids. The synthesis of these materials relies on central-ring prefunctionalized pentiptycene building blocks. A useful approach toward the preparation of these building blocks is the derivatization of pentiptycene quinone.

\section{Introduction}

Iptycenes are a class of structurally unique compounds consisting of arenes that are fused together through the bicyclo[2.2.2] octane framework. The name iptycene originated from the basic unit triptycene (1), which was first synthesized and named by Bartlett in 1942. ${ }^{1}$ To describe the extended iptycene structure, a prefix is added to indicate the number of independent arenes. ${ }^{2}$ For example, iptycenes of five and seven arenes are called pentiptycenes and heptiptycenes, respectively. Since the parent name triptycene refers to compound $\mathbf{1}$, where the arenes are all benzenoid, all the parent names of larger iptycenes such as pentiptycene and heptiptycene have been referred to the all-benzene species. However, it should be noted that there is more than one structural isomer for pentiptycene and larger iptycenes. For example, both compounds $\mathbf{2}$ (para-pentiptycene) and $\mathbf{3}$ (ortho-pentiptycene) are pentiptycenes and both compounds $\mathbf{4}$ and $\mathbf{5}$ are heptiptycenes. ${ }^{3}$ Hart et al. have suggested a set of descriptors for precisely defining the structure of iptycenes. ${ }^{2}$ For example, compounds

${ }^{a}$ Department of Chemistry, National Taiwan University, Taipei,

Taiwan 10617

${ }^{b}$ Department of Chemistry, National Central University, Chungli, Taiwan 32054

2 and $\mathbf{3}$ are named as $\left[1.1 .1^{\mathrm{b}} .1 .1\right]$ pentiptycene and $\left[1.1 .1^{\mathrm{a}} .1 .1\right]$ pentiptycene, respectively, where the 1 's indicate that each ring is benzenoid and the superscripts ( $a$ and $b$ ) refer to the bond to which the $\mathrm{sp}^{3}$ carbons are attached. In this article, the pentiptycene scaffold under discussion refers to the para-pentiptycene 2 .

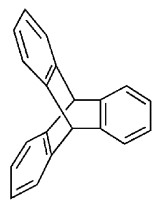

1

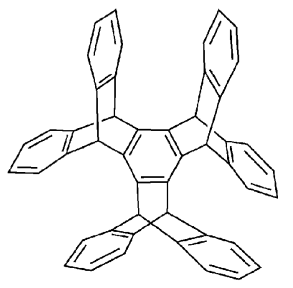

4

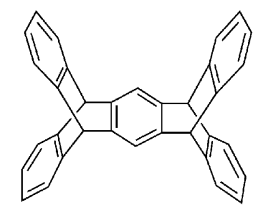

2

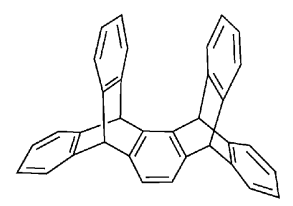

3

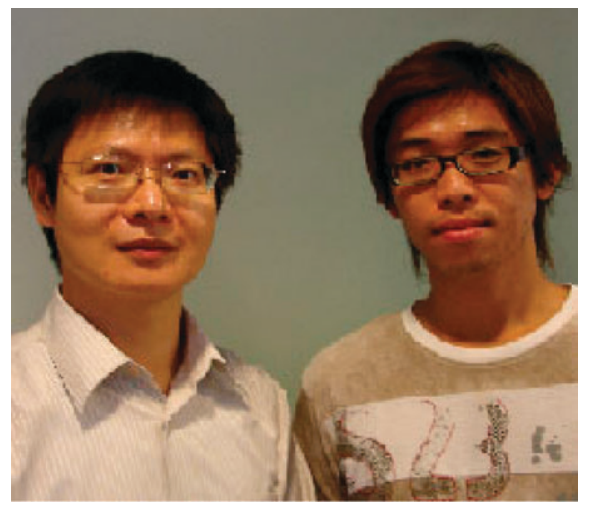

Jye-Shane Yang and Jyu-Lun Yan

Jye-Shane Yang received his PhD degree from Northwestern University (with F. D. Lewis) in 1997. He then joined T. M. Swager's group as a postdoctoral associate at Massachusetts Institute of Technology. He started his independent research at National Central University, Taiwan in 1998. In 2005, he moved back to his alma mater, National Taiwan University and was promoted to a full professor in 2007. His current research interests include photochemistry and photophysics of donor-acceptor molecules and synthesis and optoelectronic properties of $\pi$-conjugated molecular systems in solutions and thin solid films.

Jyu-Lun Yan obtained his MS degree (with J.-S. Yang) from National Central University in 2004. He is now pursuing his PhD degree with Prof. Jye-Shane Yang. His research focused on the synthesis and photophysical properties of pentiptycenederived oligo(p-phenyleneethynylene)s. 
The structural rigidity, nonplanarity, bulkiness, and $\pi$-electron richness of iptycenes, particularly the basic triptycene scaffold, have found versatile usages in constructing molecules of both fundamental and practical importance. For example, it has long been recognized that the torsional barrier for a bridgehead substituent is generally high and in some cases the atropisomers could be isolated (e.g., $6 \mathbf{6}$ and $\mathbf{6 b}) .{ }^{4}$ Such a behavior has recently been employed for the investigation of intramolecular arene-arene interactions ${ }^{5}$ and for the design of molecular rotors (7). ${ }^{6}$ In addition, functionalization of the peripheral phenyl rings can lead to liquid crystalline materials $(\mathbf{8}),{ }^{7}$ ligands for catalysis (9), ${ }^{8}$ and a variety of solid-state supramolecular architectures. ${ }^{9}$ Furthermore, end-capping of the functional moiety with bulky iptycene groups can spatially reduce its interactions with the surroundings and thus enhances the desired chemical or optoelectronic properties. Examples include kinetic stabilization of a reactive center such as carbon radical or carbene (10), ${ }^{10}$ creation of free volumes in aggregates or the solid state for skeletal movements (11), ${ }^{11}$ and prevention of $\pi$-stacking of luminophores (12 and 13) in thin solid films in order to improve the light-emitting efficiency. ${ }^{12}$

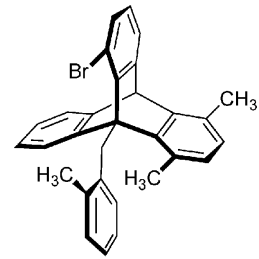

6a

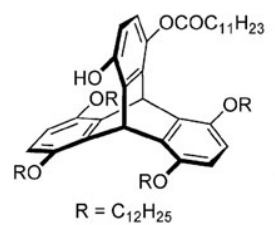

8

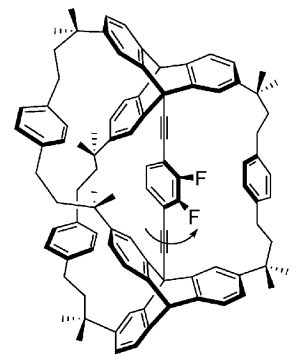

11

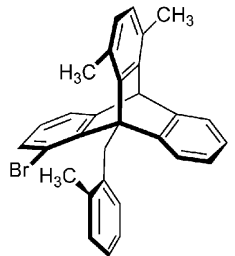

6b

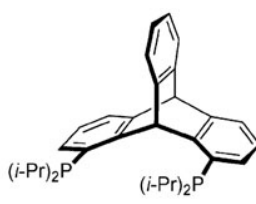

9

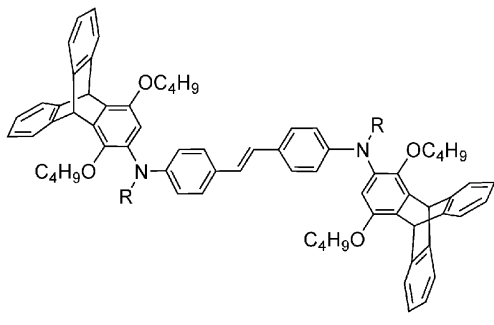

$12 \mathrm{R}=\mathrm{CH}_{3}$

$13 \mathrm{R}=\mathrm{Ph}$
Although larger iptycenes possess their own structural uniqueness, particularly in the presence of 'sterically shielded' central arene(s), the application of pentiptycene and larger iptycenes is much less explored than that of triptycene. An obvious obstacle is the synthetic concerns, since the use of larger iptycenes requires more synthetic effort. ${ }^{13}$ The synthetic difficulties in extending the iptycene framework are in part reflected by the fact that the first synthesis of pentiptycene $\mathbf{2}$ is 32 years later than the case of triptycene. ${ }^{14}$ In addition, presumably due to the steric hindrance and poorer solubility, the chemical reactivity of the central ring has been shown to be much lower than that of the peripheral rings. For instance, an attempt to prepare the diiodopentiptycene $\mathbf{1 4}$ from pentiptycene quinone 15 by following the method for the conversion of the triptycene quinone $\mathbf{1 6}$ to the diiodotriptycene $\mathbf{1 7}$ via the intermediates 18 and 19 (Scheme 1) was unsuccessful. ${ }^{15}$

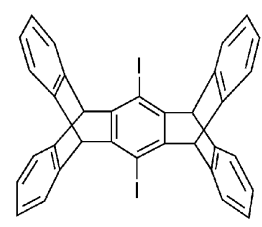

14

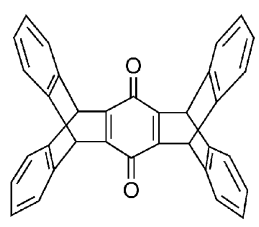

15
To expedite the chemistry of pentiptycene and larger iptycenes, facile synthetic methods for the central-ring functionalization are an important requirement. In addition, more examples of unique application of the central rings should be demonstrated. In this context, our research group has been exploring the chemistry of pentiptycene $\mathbf{2}$, since it is the smallest iptycene member that possesses a sterically shielded central benzene ring. This article will describe our previous efforts as well as the recent progress of pentiptycene chemistry in the literature.

\section{Synthesis of the pentiptycene building blocks}

The first synthesis of pentiptycene $\mathbf{2}$ was reported by Skvarchenko in 1974 through a three-step route starting with 2-aminotriptycene (Scheme 2). ${ }^{14}$ The pentiptycene scaffold was created in the last step through the Diels-Alder reaction of triptycene benzyne (2,3-didehydrotriptycene) and anthracene, but the yield was only $10 \%$. In 1981, Hart et al. reported a one-step synthesis of pentiptycene with improved yield $(26 \%$ based on the product, but $94 \%$ based on consumed anthracene). ${ }^{2}$ The reaction also followed the benzyne-anthracene Diels-Alder reaction strategy with the starting materials 1,2,4,5-tetrabromobenzene and anthracene (Scheme 3).

According to the above methods, functionalized pentiptycene can be prepared from prefunctionalized benzyne and/or anthracene or from the functionalization of the parent pentiptycene 2 . The former has been demonstrated by Hart et al. for the synthesis of compounds $\mathbf{2 0}$ and $\mathbf{2 1}$ with starting materials 1,2,4,5-tetrabromo-3,6-dimethylbenzene and

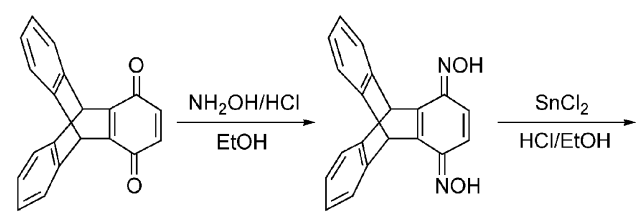

16
18

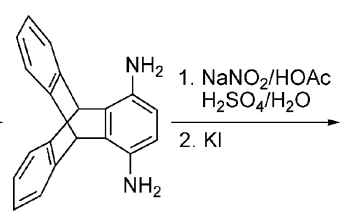

19

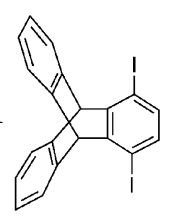

17

Scheme 1 


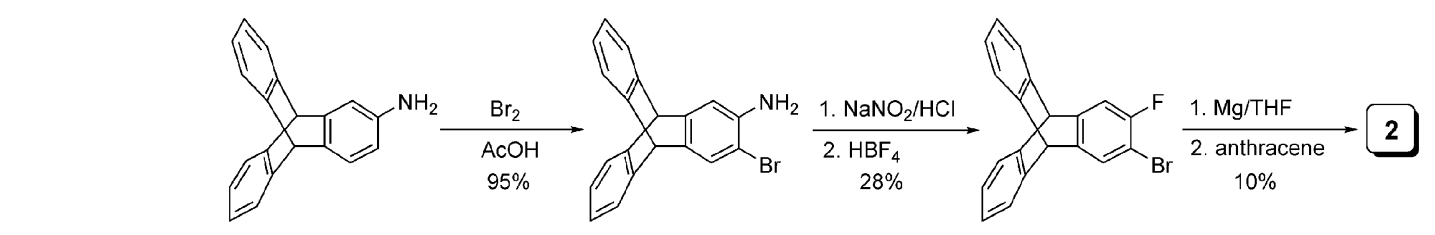

Scheme 2

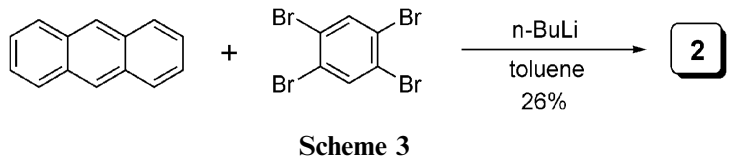

1,2,4,5-tetrabromo-3,6-dimethoxybenzene, respectively. ${ }^{2}$ However, the latter strategy has not been explored, presumably due to the difficulty in controlling the regio-, stereo-, and stoichiometric chemistry of the aromatic substitution reactions in such a symmetric polyarene system.

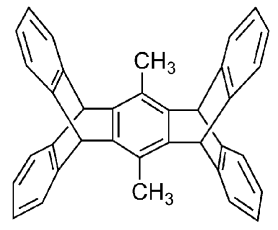

20

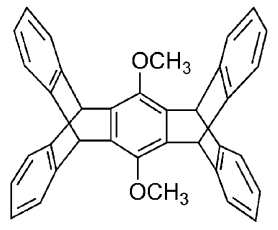

21
Regarding the central-ring functionalization of pentiptycene, a more effective and versatile method is the derivatization of the pentiptycene quinone (15) precursor, which in turn can be readily prepared from benzoquinone and anthracene through Diels-Alder reactions. Indeed, the first synthesis of $\mathbf{1 5}$ was reported along with that of $\mathbf{1 6}$ in $1931,{ }^{16}$ which is more than 40 years earlier than that of $2 .{ }^{14}$ However, the four-step synthesis of $\mathbf{1 5}$ did not lead to a satisfactory yield (Scheme 4, route $a)$. A more efficient two-step synthesis of $15(34 \%$, crude) with the same starting materials by changing the reaction conditions was reported by Theilacker et al. in 1960 (Scheme 4 , route $b$ ). ${ }^{17}$ The uncharacterized intermediate products of the first-step reaction were shown later (in 1998) by Yang and Swager to be a mixture of triptycene hydroquinone (22) and pentiptycene hydroquinone (23) with a poor solubility in both polar and nonpolar solvents. ${ }^{18}$ Conversion of $\mathbf{2 3}$ to 15 can be readily achieved with potassium bromate in acetic acid and the overall yield was slightly larger (39\% in route $c$ of Scheme 4). More recently, Chen et al. adopted another twostep route via the intermediate $\mathbf{1 6}$ to prepare $\mathbf{1 5}$ by adding $p$-chloranil, and the overall yield can be improved to $68 \%$ (Scheme 4, route $d$ ). ${ }^{19}$ Compound 15 can also be prepared from 21 through the intermediate $\mathbf{2 3}$, but the overall yield starting from anthracene is only $18 \% .^{2}$

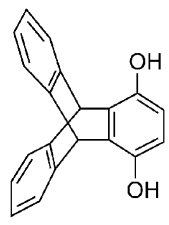

22

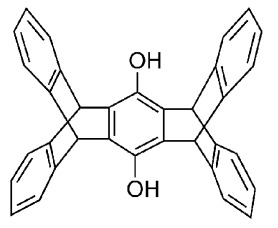

23
Although pentiptycene quinone $\mathbf{1 5}$ is a potential precursor for many other central-ring disubstituted pentiptycenes in

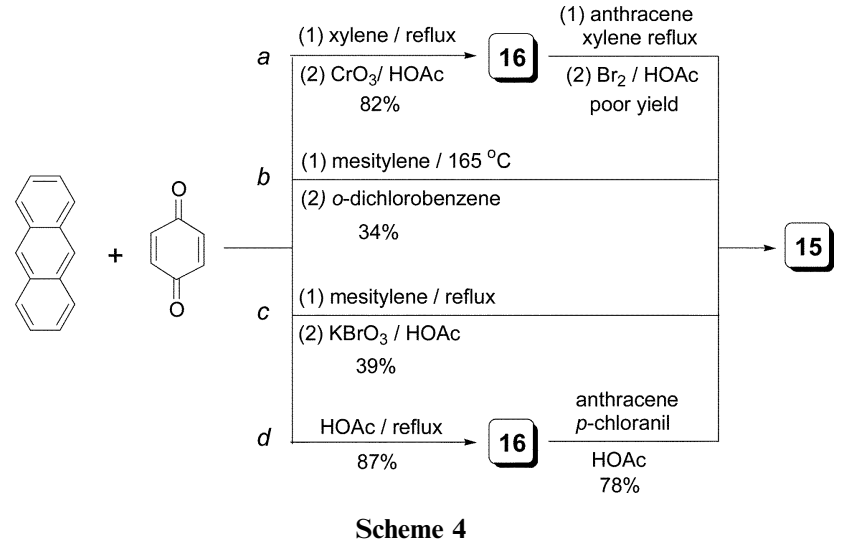

addition to the reduced form 23, the real demonstration of such a utility was not reported until 1998, when Yang and Swager reported the synthesis of pentiptycene diacetylene 24 (Scheme 5). ${ }^{18}$ The reaction started with a nucleophilic addition of lithium trimethylsilylacetylide to $\mathbf{1 5}$ followed by reductive aromatization of the central ring, which produced the trimethylsilyl-protected diethynylpentiptycene 25. Deprotection of the TMS group provided compound $\mathbf{2 4}$. When one equivalent of lithium trimethylsilylacetylide is used, the monoacetylene adduct $\mathbf{2 6}$ can be prepared. ${ }^{20}$

It took another eight years to uncover more new chemistry of 15, which leads to several central-ring unsymmetrically

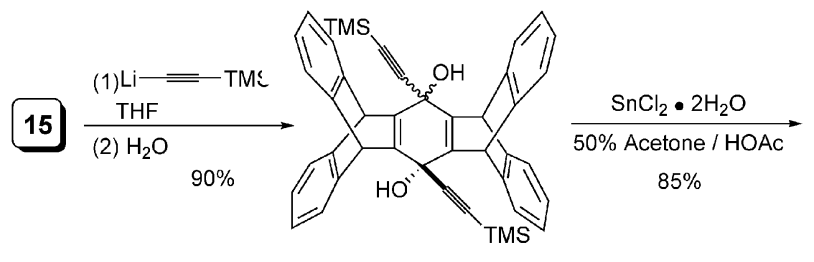

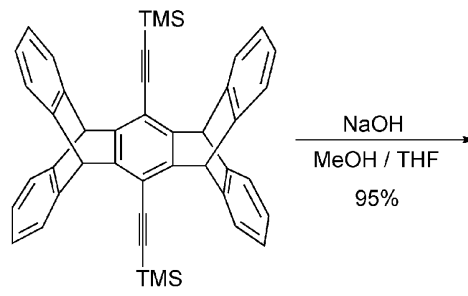

25

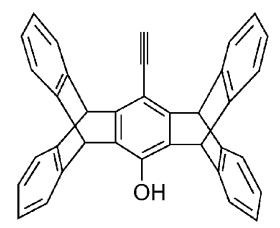

26

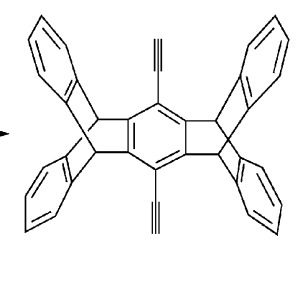

24 

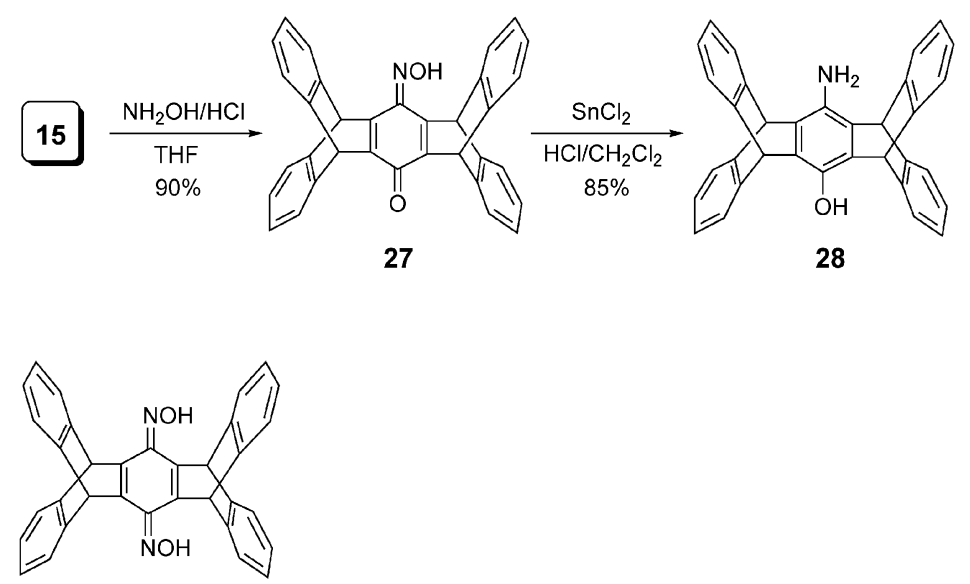

29

Scheme 6

disubstituted pentiptycenes, where iodo, bromo, amino, nitro, cyano, and formyl groups are introduced. ${ }^{21}$ The key reaction is the conversion of one of the carbonyl groups of $\mathbf{1 5}$ to oxime (27), which in turn can be reduced to form the aminophenol 28, an important precursor for Sandmeyer reactions (Scheme 6). As mentioned in the Introduction, an attempt to convert $\mathbf{1 5}$ to pentiptycene dioxime $\mathbf{2 9}$ by following the same reaction conditions as in Scheme 1 has failed. ${ }^{15}$ However, the monooxime product 27 can be obtained in high yields when the ethanol solvent in the first-step reaction is replaced with THF. The amino group in $\mathbf{2 8}$ can be either removed to form the pentiptycene phenol $\mathbf{3 0}$ or converted to a nitro group (i.e., compound 31) under slightly different reaction conditions (Scheme 7). The conversion of amino to nitro group by tert-butyl nitrite in the case of $\mathbf{2 8}$ is particularly interesting, since similar reactions have not been reported in the literature. Control experiments have shown that the presence of $\mathrm{H}_{3} \mathrm{PO}_{2}$ is critical. However, application of this method to simple arylamines only leads to moderate or poor yields of nitroarenes. Apparently, the pentiptycene scaffold plays an important role in accounting for the high efficiency of amino $\rightarrow$ nitro transformation. Since a phenyl radical is more likely involved in the reaction, ${ }^{22}$ this might indicate a greater stability of the pentiptycene radical vs. simple planar phenyl radicals. Upon $O$-alkylation of 30, the resulting product can be further functionalized with a bromo, iodo, cyano, or formyl group at the position para to the alkoxy group (e.g., compounds 32-35). ${ }^{21}$

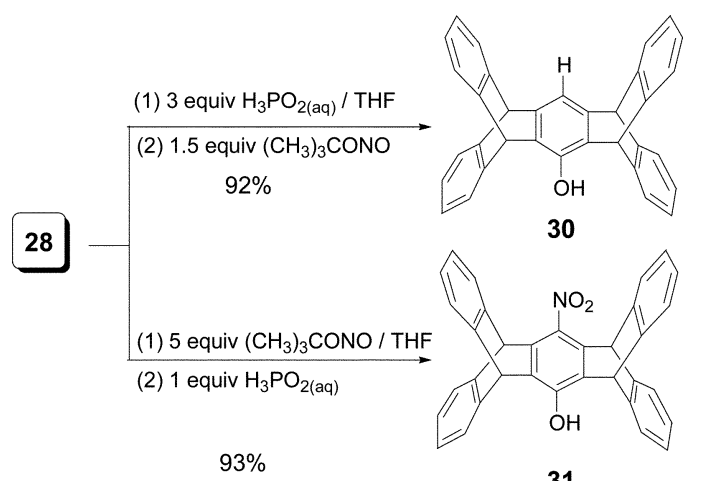

Scheme 7

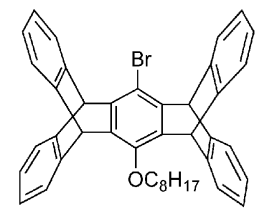

32

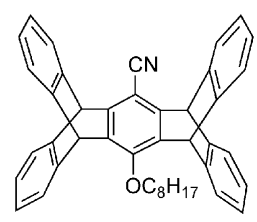

34

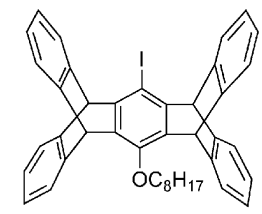

33

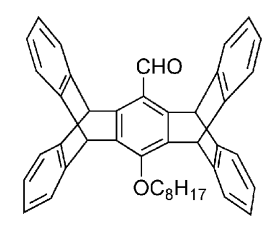

35
Having these pentiptycene building blocks in hand, further derivatization of the central ring becomes straightforward. For example, pentiptycene hydroquinone $\mathbf{2 3}$ can react with alkyl halides, acid chlorides, and sulfonyl chlorides to form $O$-alkylated products, esters, and sulfonates, respectively. In addition, pentiptycene diacetylene $\mathbf{2 4}$ can react with dihaloarenes via the Sonogashira reaction to form pentiptycenederived poly(phenyleneethynylene)s. Moreover, the Heck and Suzuki as well as the Sonogashira coupling reactions can be carried out on the halogenated pentiptycene (e.g., compound 33), as demonstrated by the formation of the pentiptycene-derived stilbene 36, biphenyl 37, and phenylacetylene $\mathbf{3 8}$ from reactions with styrene, phenylboronic acid, and trimethylsilylacetylene, respectively. ${ }^{21}$ It should be noted that, unlike the planar aryl triflates, ${ }^{23}$ attempts to carry out these coupling reactions with pentiptycene monotriflate (39) or pentiptycene bistriflate (40) have failed, and the product obtained from the reaction of the latter is generally the pentiptycene quinone $\mathbf{1 5}$ due to triflate hydrolysis and the oxidation of the resulting hydroquinone. ${ }^{24}$ We have also adopted an iterative synthetic method resembling the strategy for the preparation of pentiptycene diacetylene $\mathbf{2 4}$ (Scheme 5) to prepare a series of acetylene-bridged pentiptycene dimer (41), trimer (42), and tetramer (43) from the building blocks $\mathbf{1 5}, \mathbf{2 6}$, and $33 .{ }^{20}$ The unique properties associated with some of these pentiptycene derivatives are discussed in the following section. 


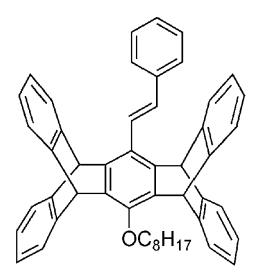

36

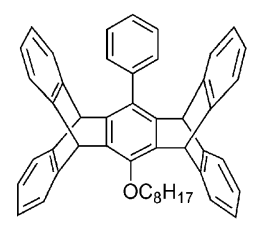

37

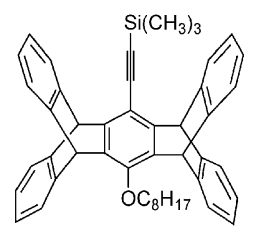

38

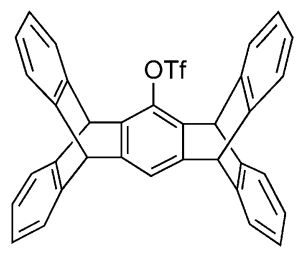

39

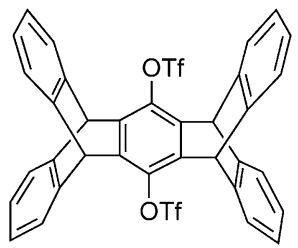

40

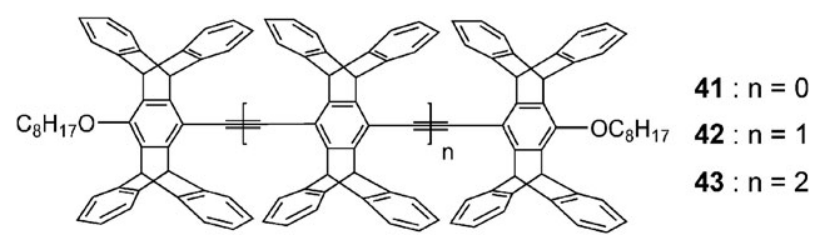

\section{Application of the pentiptycene scaffold}

Since the most prominent difference between pentiptycene and triptycene is the presence of a sterically shielded central ring in the former, the major reason for choosing the pentiptycene rather than the triptycene scaffold would be associated with the central ring. In the following, a few typical applications of central-ring functionalized pentiptycenes are illustrated.

(a) Creation of porous films with bright luminescence for $\pi$-conjugated polymers

The introduction of the bulky pentiptycene framework to $\pi$-conjugated polymers was first carried out by Yang and Swager (i.e., 44) in order to prepare stable fluorescent polymer films by preventing $\pi$-stacking or excimer formation between the polymer backbones. ${ }^{18}$ Indeed, polymer $44\left(M_{\mathrm{n}}=56000\right)$ displays 3.5 times larger fluorescence quantum yield than the planar model polymer $45\left(M_{\mathrm{n}}=33000\right)$ in thin solid films. In addition, films of $\mathbf{4 4}$ display great spectroscopic stability and reproducibility, but different films of $\mathbf{4 5}$ show different fluorescence profiles, presumably due to different degrees of interchain interactions. It should also be noted that the solubility of polymer 44 in organic solvents is 100 -fold larger than that of 45, even though the latter has more than double the density of the solubilizing side chains. More importantly, the fluorescence of films of $\mathbf{4 4}$ undergoes fast response to the vapor of benzoquinones and nitroarenes, including the highly explosive 2,4,6-trinitrotoluene (TNT) (Fig. 1), which possesses a saturation vapor pressure of only $8.02 \times 10^{-6} \mathrm{mmHg}$ or about $10 \mathrm{ppb}$ at $22{ }^{\circ} \mathrm{C} .{ }^{25}$ Since benzoquinones and nitroarenes are good electron acceptors, ${ }^{26}$ the mechanism of fluorescence quenching can be attributed to the occurrence of electron transfer from the excited polymer to the electron acceptors. The amount of fluorescence quenching depends on the quenchers, the exposure times, and the film thickness. With

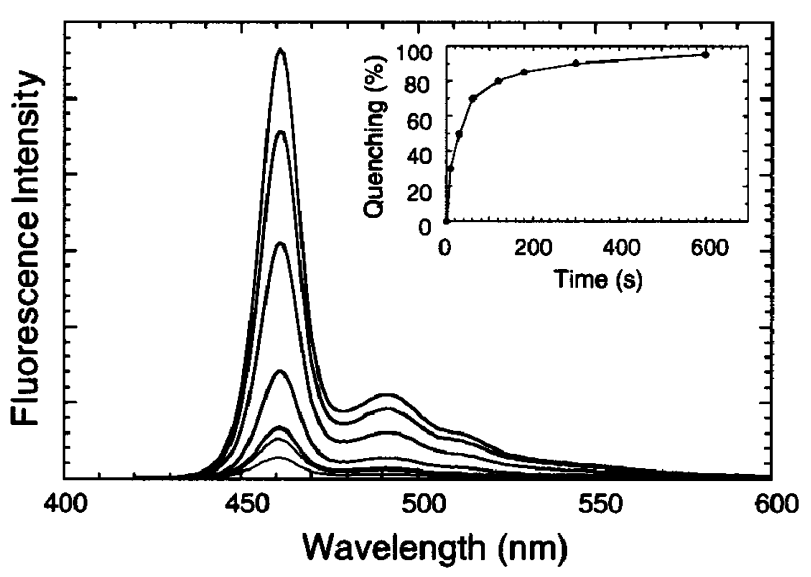

Fig. 1 Time-dependent fluorescence intensity of $\mathbf{4 4}$ in a $25-\AA$ film upon exposure to TNT vapor (room temperature) at $0-600 \mathrm{~s}$ (top to bottom), and the fluorescence quenching (\%) as a function of time (inset). Reproduced with permission from J. Am. Chem. Soc., 1998, 120, 5321. ${ }^{18}$ C 1998 , American Chemical Society.

the same exposure time, stronger fluorescence quenching was observed for TNT in thinner films, but the opposite is true for benzoquinone (BQ). These phenomena indicate that the polymer films have a porous nature and BQ diffuses more readily than TNT toward the interior cavities of the films due to weaker BQ-polymer $v s$. TNT-polymer interactions. The origin of the porosity of films of $\mathbf{4 4}$ can be mainly attributed to the nonplanar $\mathrm{H}$-shaped scaffolds of pentiptycene. An idealized model is shown schematically in Fig. 2.
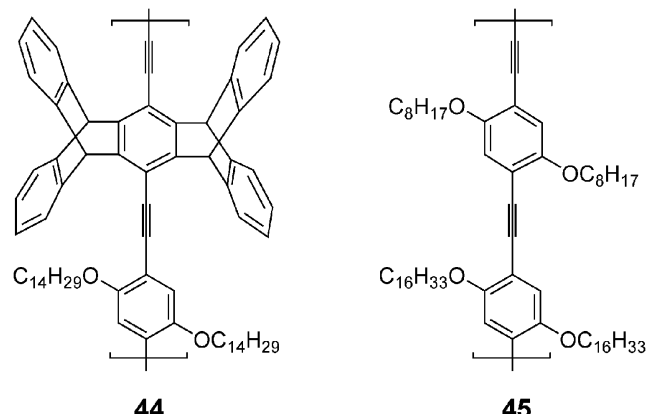

45

The success of TNT detection with films of $\mathbf{4 4}$ has led to a commercially available device, called 'FIDO', which allows for real-time monitoring of the fluorescence intensity of the

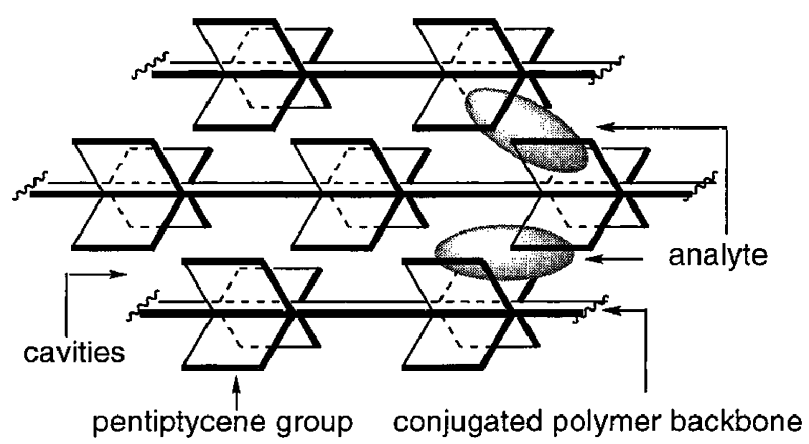

Fig. 2 A conceptual and idealized model showing the porous structure of $\mathbf{4 4}$ in thin solid films. Reproduced with permission from J. Am. Chem. Soc., 1998, 120, 5321. ${ }^{18}$ (C) 1998, American Chemical Society. 
polymer films with femtogram detection limits. ${ }^{27}$ In field tests with buried land mines, the sensitivity and selectivity of FIDO are comparable to those of trained canines and it is currently one of the best real-time land mine-detecting technologies.

Many other pentiptycene-derived poly(phenyleneethynylene)s (PPEs, 46) were later prepared by the Swager group through changing the arene moiety in $\mathbf{4 6}$ and investigated as fluorescent chemosensors for not only nitroarenes but also other analytes. ${ }^{28-32}$ For example, introduction of the strong hydrogen bond-donating hexafluoro-2-propanol groups to the terminal of the solubilizing side chains leads to conjugated polymers (e.g., polymer 47) with fluorescence-quenching responses to the vapors of pyridine and 2,4-dichloropyrimidine. $^{29}$ In addition, replacement of the alkoxy side chains with dioctylamino groups results in conjugated polymers (e.g., polymer 48) that display an 'off-on' fluorescence sensing mode to hydrazine vapor. ${ }^{30}$ The hydrazine-induced fluorescence enhancement has been attributed to the removal of some oxidized traps along the polymer backbone by reduction with hydrazine. The number of oxidized trap sites is expected to be larger for thin films of $\mathbf{4 8} \mathrm{vs.} \mathbf{4 4}$ due to the more strongly electron-donating amino substituents. For the purpose of TNT sensing, thin films of both the dibenzochrysene-pentiptycene copolymer 49 and the chiral side chain derivative $\mathbf{5 0}$ display higher sensitivity to TNT than those of $44 .^{31,32}$ The improved TNT sensitivity of $\mathbf{4 9} v s$. 44 can be attributed to its longer excited-state lifetime $\left(\tau_{\mathrm{f}}=2.5 v s .0 .5 \mathrm{~ns}\right.$ in dichloromethane), which allows for longer-range through-bond exciton migration. ${ }^{31}$ In contrast, the superior TNT sensitivity of $\mathbf{5 0} \mathrm{vs}$. 44 is a consequence of the formation of aggregates with a threedimensional chiral gridlike structure. ${ }^{32}$ The films of such aggregates possess both higher fluorescence quantum efficiency $(\Phi=0.61)$ and better interchain exciton transport than those of polymer 44. As evidenced by the much lower fluorescence quantum yield ( $\Phi=0.3$ ) for the aggregates consisting of $50 \%$ $(R)-\mathbf{5 0}$ and $50 \%(S)-\mathbf{5 0}$, the performance of the films is critically associated with the chirality of the films.

In addition to PPEs, several all-iptycene-based conjugated polymers such as poly(iptycenebutadiynylene)s (PPDs) 51-53 have been investigated as TNT sensors. ${ }^{33}$ Compared to $\mathbf{4 4}$, these polymers display higher affinity to TNT in solutions, but they display slower fluorescence quenching and recovery rates in thin films in the presence and upon removal of TNT vapors, respectively. Inhomogeneous distribution of TNT molecules on the surface of the films due to tight binding might account for the results. The results also show that it is not always a merit to have strong TNT-polymer interactions in the design of thin film-based TNT sensors.

The pentiptycene scaffold has also been employed to form a platinum acetylide polymer (54) for investigating the effect of the interchain interactions on the triplet excited state. ${ }^{34}$ As compared with the parent polymer 55, which shows aggregate

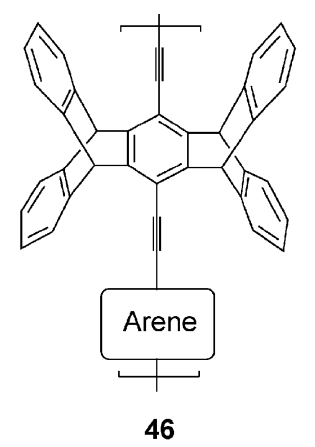

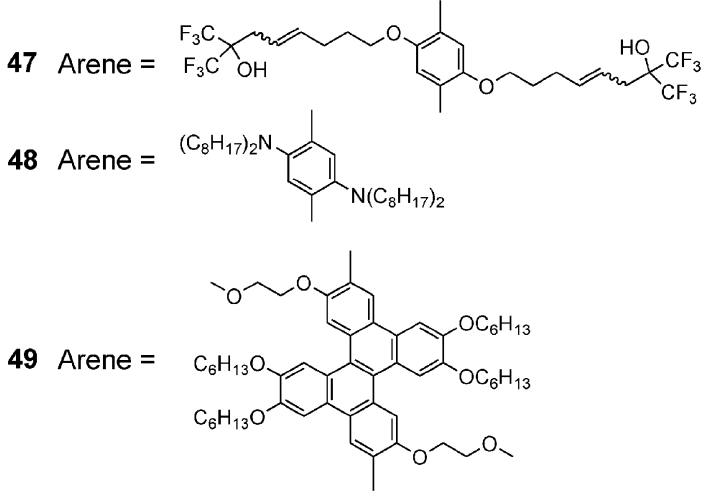

50 Arene $=$<smiles>Cc1cc(OCCCC(C)CCCC(C)C)c(C)cc1OCCCCC(C)C</smiles>

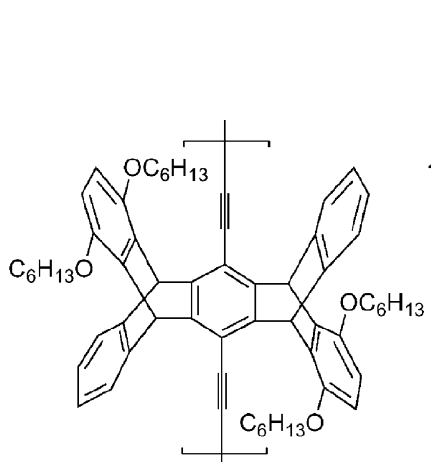

51

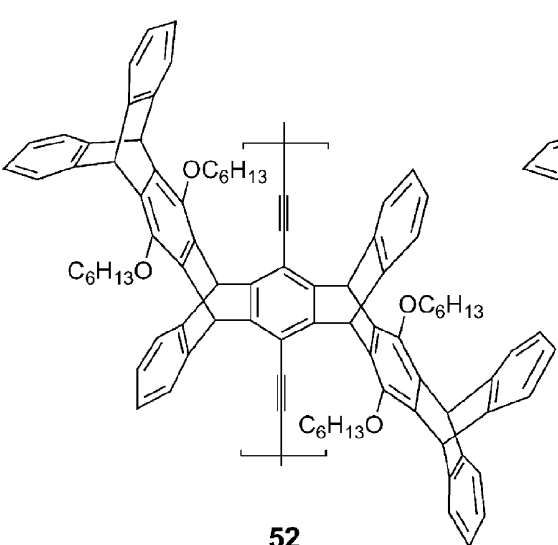

52

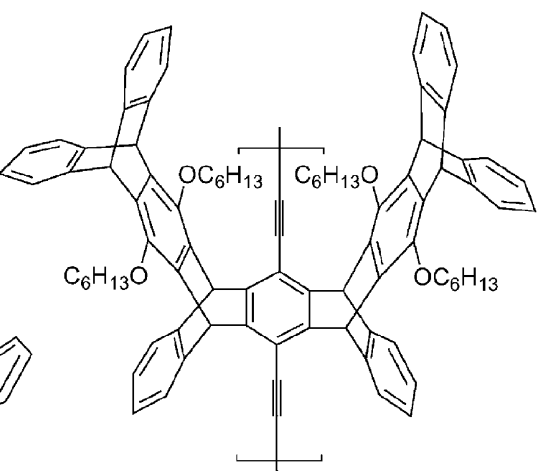

53 
formation in both THF solutions and thin solid films, polymer $\mathbf{5 4}$ is free of noticeable interchain interactions even in the solid films. The presence of significant interchain interactions in $\mathbf{5 5}$ imposes a significant effect on the photophysical properties. For example, the triplet lifetime is much shorter for $\mathbf{5 5}$ vs. 54 (0.9 vs. $63 \mu \mathrm{s})$ in THF. In addition, the solid-state phosphorescence is dramatically reduced for $\mathbf{5 5}$ on going from THF solutions to thin films due to stronger interchain interactions. The aggregation effect might result from interchain $\pi-\pi$ interactions that affect the $\mathrm{T}_{1}-\mathrm{S}_{0}$ energy gap or from metal-metal $\mathrm{d}-\mathrm{p}$ interactions that lead to a low-energy excited state.

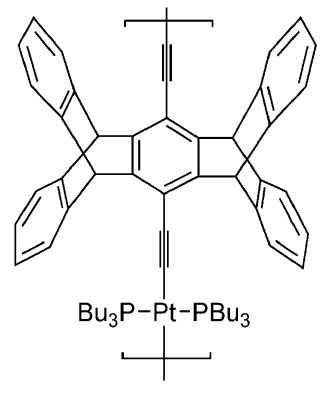

54

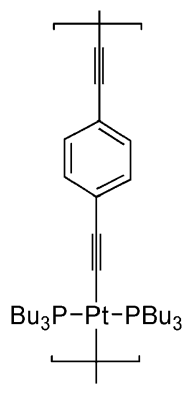

55 (b) Creation of porous networks or free volume in the solid state

Organic porous materials with tubular channels have long been the subject of research interest. ${ }^{35-37}$ For one reason, the self-assembly of molecules toward porous networks is dictated by the weak noncovalent bonding interactions, understanding of which is crucial in the progress of supramolecular chemistry. In addition, they have potential applications in chemical adsorption and catalysis, resembling the inorganic zeolites. ${ }^{38}$ However, the formation of a large free volume in crystals is against the inherent close-packing propensity of molecules in crystals. Thus, a popular approach is to adopt macrocyclic molecules, ${ }^{36,37}$ because stacking of these types of molecules can directly lead to tubular channels created by the pre-formed molecular cavity. Recent examples included the triptycene-derived macrocycles $\mathbf{5 6}^{37}$

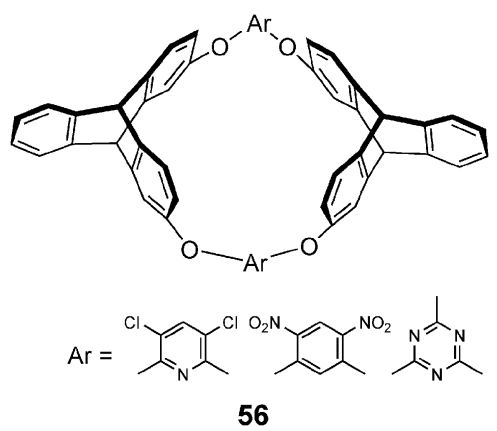

Pentiptycene-derived macrocycles have not yet been reported. However, the cavity-forming propensity of pentiptycene derivatives has been demonstrated. ${ }^{18}$ A particularly intriguing case is the pentiptycene diamide 57, which forms rectangular channels in the crystals (Fig. 3). ${ }^{39}$ The secondary amide group was originally introduced to create hydrogenbonding networks, but it turned out to be silent in the final crystal structure. Instead, $\pi-\pi$ stacking interactions dominate the non-covalent interactions in determining the porous (a)

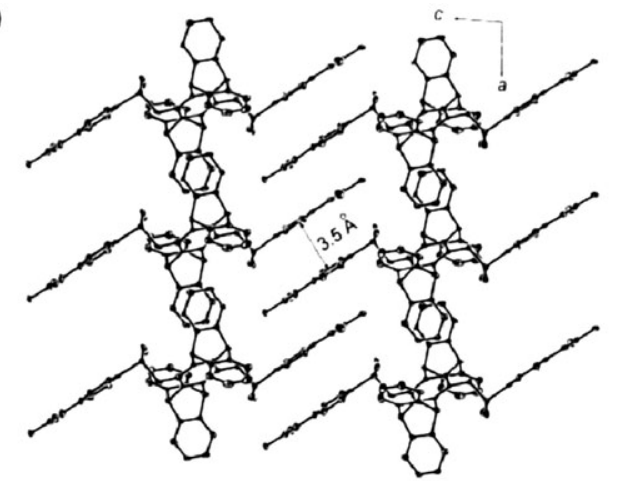

(b)

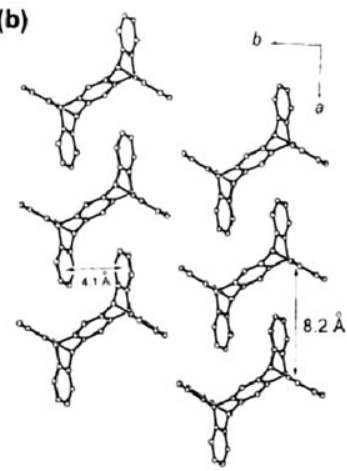

(c)

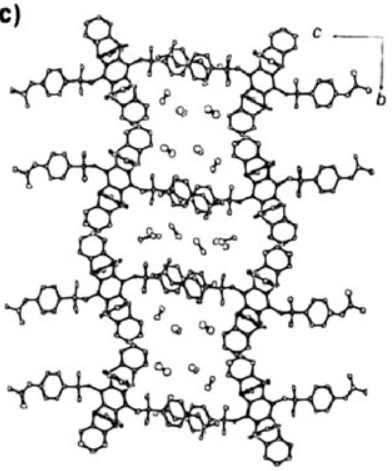

(d)

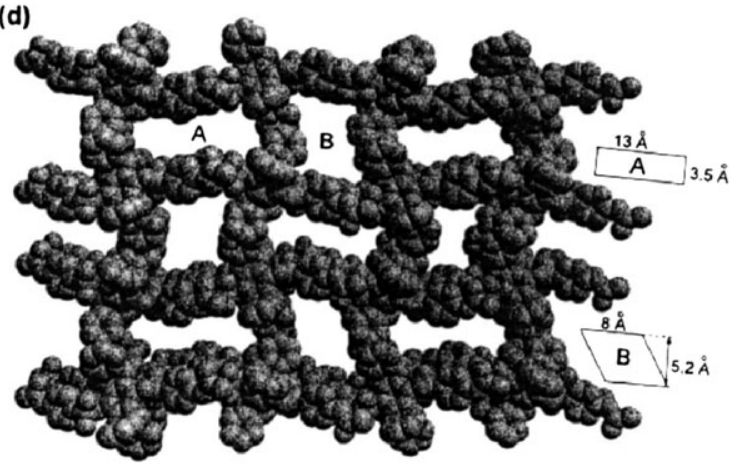

Fig. 3 Crystal packing diagrams of $\mathbf{5 7}$ showing (a) the extended conformation and the stacking of $N$-acetylsulfanilyl substituents; (b) pentiptycene pillars; (c) the top view of zigzag pentiptycene walls and channels (methanol solvent molecules included), and (d) the effective sizes of channels by a space-filling model. Adapted from Tetrahedron Lett., 2000, 41, 7911.39 
packing mode. For comparison, the corresponding crystal packing in the triptycene diamide $\mathbf{5 8}$ is dictated by the intramolecular and intermolecular amide-amide hydrogen bonding as well as the intramolecular edge-to-face $\pi-\pi$ interactions. ${ }^{9 a, 39}$

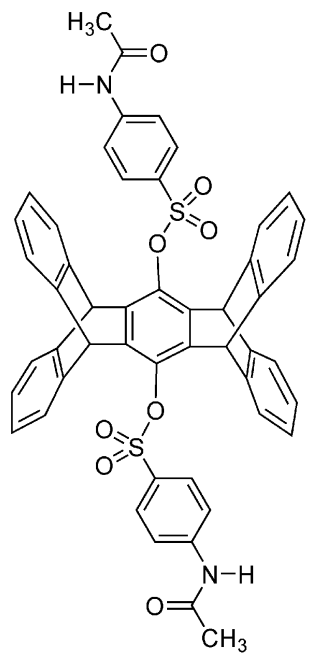

57

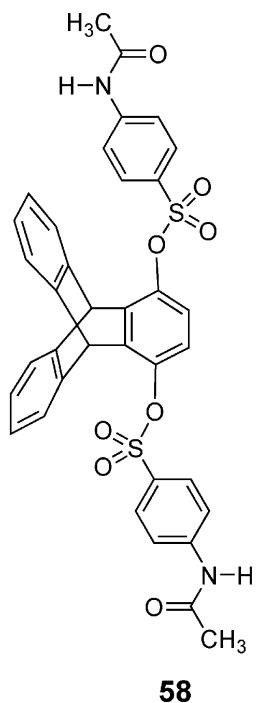

58
Long and Swager have applied the pore-forming propensity of triptycenes and pentiptycenes to design low dielectric constant (low- $\kappa$ ) materials, which might be used to manufacture denser and thus faster integrated circuits. ${ }^{40}$ The dielectric constant of porous materials can be predicted by the Bruggeman effective medium approximation: ${ }^{41}$

$$
f_{1}\left[\left(\kappa_{1}-\kappa_{\mathrm{e}}\right) /\left(\kappa_{1}+2 \kappa_{\mathrm{e}}\right)\right]+f_{2}\left[\left(\kappa_{2}-\kappa_{\mathrm{e}}\right) /\left(\kappa_{2}+2 \kappa_{\mathrm{e}}\right)\right]=0
$$

where $f_{1,2}$ are the percentages of each component, $\kappa_{1,2}$ are the dielectric constants for each compound, and $\kappa_{\mathrm{e}}$ is the dielectric constant of the composite. For example, to create low- $\kappa$ materials with a dielectric constant $(\varepsilon)$ less than 2.0 requires $70 \%$ porosity with the silica $(\varepsilon=3.9-4.5)$ matrix. Among several investigated polymers, the two most promising iptycene-derived polymers are the poly(aryl ether)s $59(\varepsilon=2.41)$ and $60(\varepsilon=$ 2.42). ${ }^{40}$ Both polymers have high thermostability with a thermal decomposition temperature above $500{ }^{\circ} \mathrm{C}$. The high thermal stability can be attributed to reduced interactions between the backbones of the neighboring chains and a rigidified solid-state structure. Another promising feature of these polymers is the low water absorption behavior, which is an important feature for maintaining a low dielectric constant in the devices.

\section{(c) Creation of ionophores for metal ion sensors}

In addition to the nonspecific recognition sites created in pentiptycene-derived polymer films (e.g., the TNT sensor 44), ${ }^{18}$ the nonplanar scaffold of pentiptycene can also be functionalized to form a more specific receptor. One such example is the metal ion sensor 61, where both the polyether and pentiptycene groups can interact with metal ions through ion-dipole and cation- $\pi$ interactions, respectively. ${ }^{42}$ The pyrene fluorophores are the fluorescence signal reporter, and the presence of both monomer and excimer emission in dichloromethane allows ratiometric measurements of the sensing behavior. Among 15 selected metal ions, $\mathrm{Ca}^{2+}$ and $\mathrm{Cd}^{2+}$ can selectively induce an enhancement of the monomer fluorescence at the expense of the excimer fluorescence (Fig. 4a). Whereas this follows the common monomer-excimer scenario for pyrene-derived fluorescent sensors, ${ }^{43}$ a new fluorescence sensing behavior was also observed for compound $\mathbf{6 1}$ in response to $\mathrm{Cu}^{2+}$ : namely, a cation-induced blue shift of the pyrene excimer emission (Fig. 4b). In conjunction with the excitation spectra and fluorescence lifetime data, the formation of static excimers with partially overlapped structure was proposed. Similar behavior was also observed later in other pyrene-derived fluorescent chemosensors. ${ }^{44}$ A schematic drawing accounting for the fluoroionophoric behavior of $\mathbf{6 1}$ is depicted in Fig. 5.

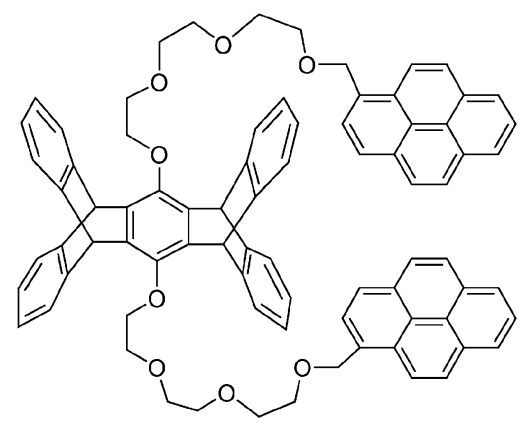

61

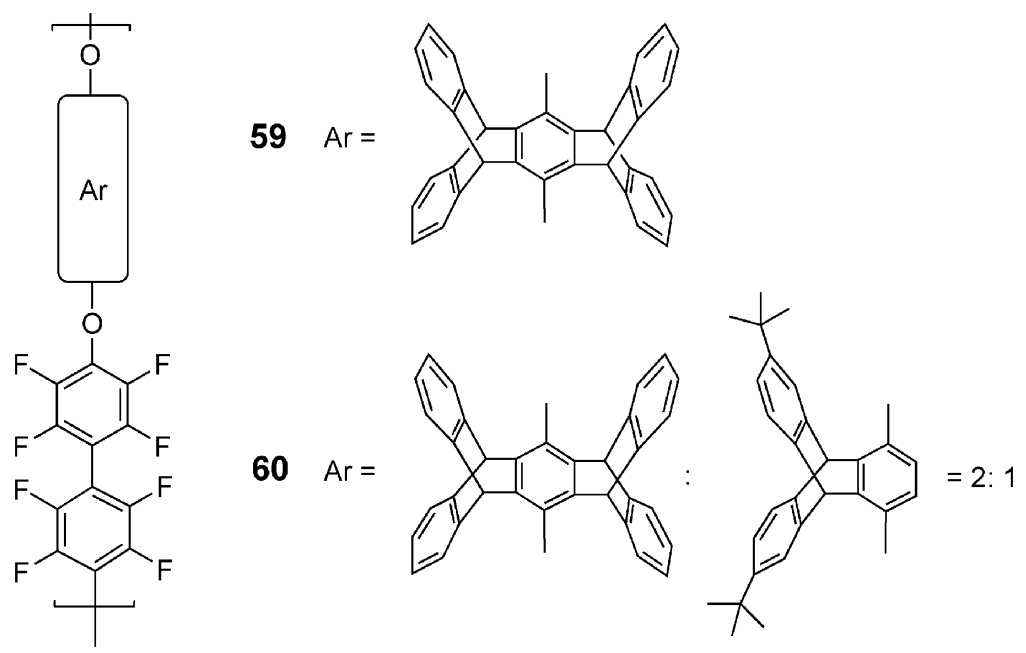



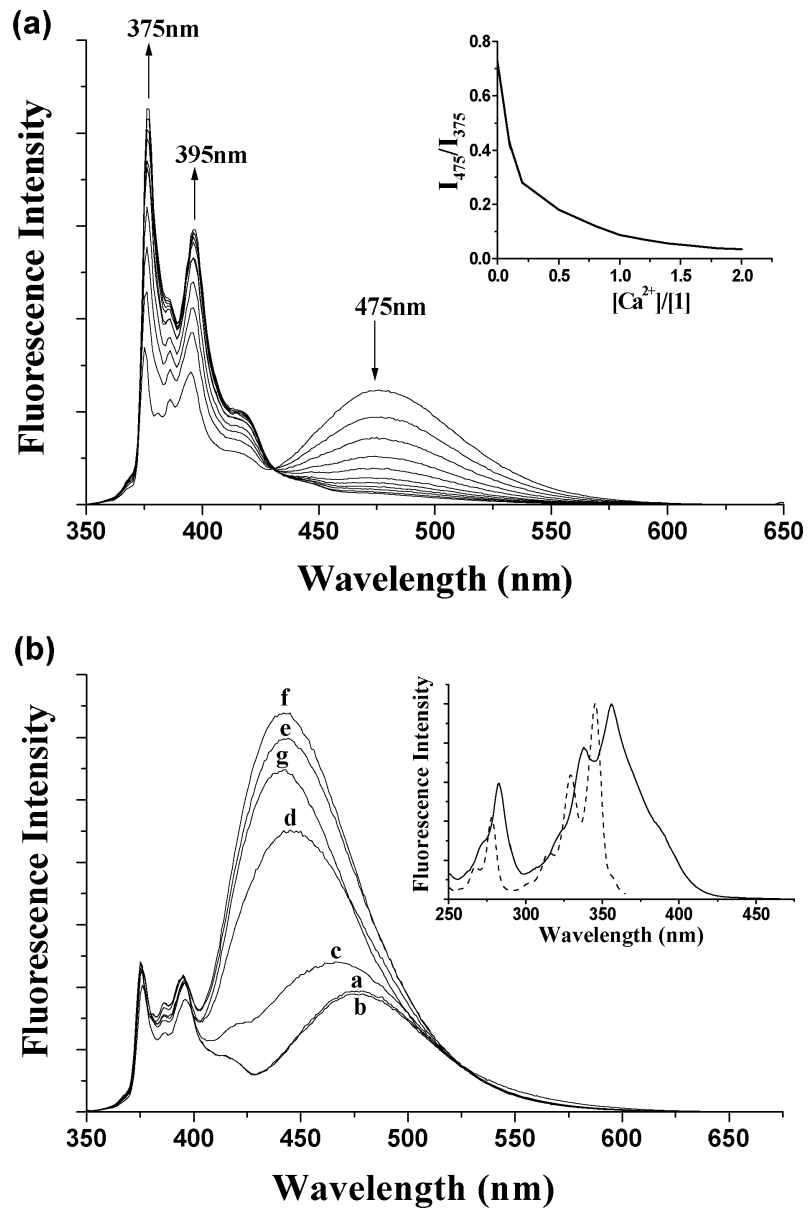

Fig. 4 (a) Fluorescence spectra of 61 in $\mathrm{CH}_{2} \mathrm{Cl}_{2}$ in the presence of 0-2.0 equiv. of $\mathrm{Ca}\left(\mathrm{ClO}_{4}\right)_{2} \cdot 4 \mathrm{H}_{2} \mathrm{O}$ predissolved in $\mathrm{MeCN}(0.005 \mathrm{M})$ and the corresponding change in the intensity ratio of the excimer $(475 \mathrm{~nm})$ vs. monomer ( $375 \mathrm{~nm}$ ) emission (inset). (b) Fluorescence spectra of $\mathbf{6 1}$ in $\mathrm{CH}_{2} \mathrm{Cl}_{2}$ in the presence of (a) 0 , (b) 1.0 , (c) 5.0, (d) 7.0, (e) 9.0 , (f) 11.0 , and $(\mathrm{g}) 15$ equiv. of $\mathrm{Cu}\left(\mathrm{ClO}_{4}\right)_{2} \cdot 6 \mathrm{H}_{2} \mathrm{O}$ predissolved in $\mathrm{MeCN}$ $(0.005 \mathrm{M})$ and the corresponding change in the excitation spectra (normalized) monitored at 375 (dashed line) and 440 (full line) $\mathrm{nm}$ (inset). Reproduced with permission from Org. Lett., 2001, 3, 889. ${ }^{42}$ C) 2001, American Chemical Society.

\section{(d) Function as a conformation regulator}

As mentioned in the Introduction, the three-dimensional scaffold of triptycene can interact with the subunits of its derivatives and then lead to specific molecular conformations.

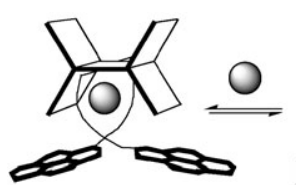

$=\mathrm{Cd}^{2+}$ or $\mathrm{Ca}^{2+}$

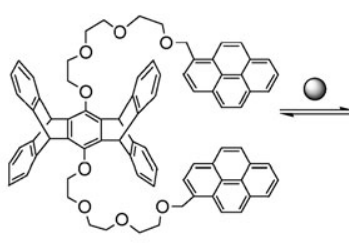

61

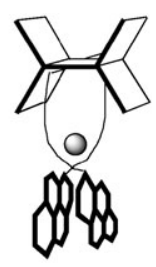

$\mathrm{O}=\mathrm{Cu}^{2+}$
Fig. 5 Schematic representation of the interactions between $\mathbf{6 1}$ and metal ions. Reproduced with permission from Org. Lett., 2001, 3, $889 .{ }^{42}$ (C) 2001, American Chemical Society.

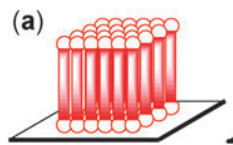

(b)

(c)

Fig. 6 Schematic representations of three distinct orientations of $\alpha, \omega$ dithiols on a metal surface corresponding to the (a) stand-up, (b) liedown, and (c) looped monolayer assembly structures.

The conformational control in these examples results from steric repulsions or certain specific non-covalent interactions. We have adopted the bulky pentiptycene scaffold to affect the conformational preference of two types of target molecules: alkanedithiols and oligo( $p$-phenyleneethynylene)s.

Control of the conformation and monolayer structure of $\alpha, \omega$-dithiols on metal surfaces has been the subject of current interest in surface chemistry and supramolecular chemistry. ${ }^{45,46}$ As schematically shown in Fig. 6, $\alpha, \omega$-dithiols can adopt at least three distinct monolayer structures on a metal surface. The stand-up structure enables $\alpha, \omega$-dithiols to serve as molecular wires connecting to two metal substrates. In contrast, both of the thiol groups can chemisorb on the same substrate to form a lie-down or a looped structure. While alkanedithiols generally adopt the stand-up structure, ${ }^{46}$ the incorporation of the pentiptycene group in the middle of the alkyl chain (i.e., compound 62) leads to the choice of a looped structure, as schematically shown in Fig. $7 \mathrm{a} .{ }^{47} \mathrm{We}$ reasoned
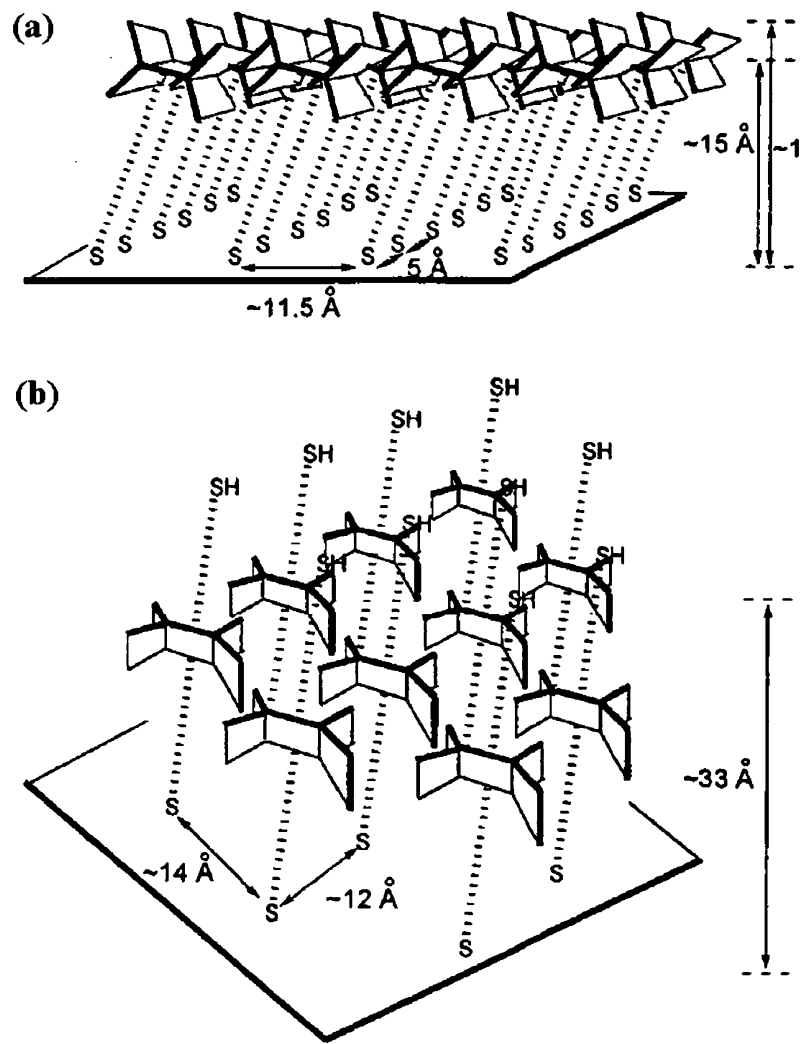

Fig. 7 Schematic representations of two proposed monolayer assembly structures of $\alpha, \omega$-dithiol $\mathbf{6 2}$ on a metal surface: (a) a folded conformation and the corresponding looped structure and (b) an extended conformation and the corresponding stand-up structure. Reproduced with permission from J. Org. Chem., 2000, 65, 871. ${ }^{47}$ (C) 2000, American Chemical Society. 
that the bulky pentiptycene groups prevent close contact of the aliphatic chains in a stand-up monolayer structure (Fig. 7b). Instead, the pentiptycene group functions as a turn unit to allow folding of the aliphatic chains, which is stabilized by intramolecular chain-chain (dispersion) interactions, and finally leads to a looped structure with the optimum $5 \AA$ chainto-chain separation. Since such a structure exposes the pentiptycene group at the monolayer-air or monolayer-liquid interface, tailoring of the pentiptycene functionality might lead to interesting surface properties.

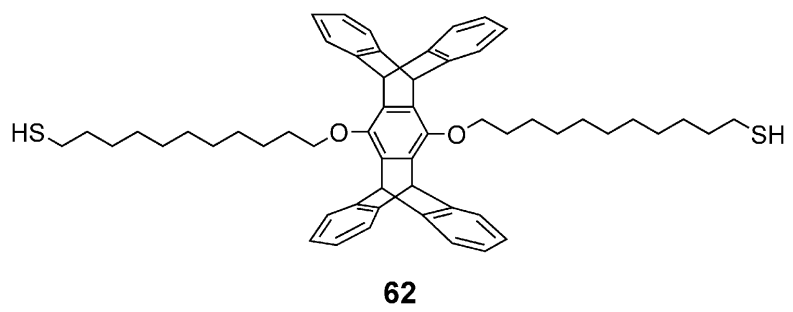

Another unique application of the bulky pentiptycene group in conformational control is to provide the first experimental evidence about the intrinsic conformation effect on the fluorescence properties of phenyleneethylene (PE) oligomers. An interesting feature associated with the conformations of $\mathrm{PE}$ oligomer and polymers is the rather

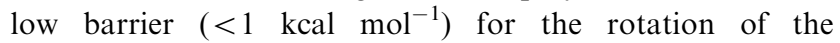
phenyl rings in the electronic ground state $\left(\mathrm{S}_{0}\right) \cdot{ }^{48}$ For example, the coplanar form of 1,4-bis(phenylethynyl)benzene (63-coplanar) was calculated to be only $\mathrm{ca}$. $0.2 \mathrm{kcal} \mathrm{mol}^{-1}$ lower in energy than the twisted form (63-twisted). ${ }^{49}$ For comparison, the rotational barrier for a simple molecule such as ethane is more than 10-fold larger (ca. 3.0 $\left.\mathrm{kcal} \mathrm{mol}^{-1}\right) .{ }^{50}$ Such a behavior is apparently associated with the cylindrical symmetry of the ethynyl groups, which maintain considerable conjugation interactions between the adjacent phenyl groups upon their rotations. In contrast, the corresponding calculations predict a deep potential energy surface for the lowest excited state $\left(S_{1}\right)$ of $\mathbf{6 3}$ with a minimum at the coplanar conformation. ${ }^{48}$ This in turn suggests that the fluorescence of a coplanar form would be red-shifted with respect to that of a twisted form. However, previous attempts to obtain the corresponding experimental information had been unsuccessful due to the barrierless conformational relaxation in $S_{1}$, which results in fluorescence only from the coplanar form. The appearance of both the $S_{0}$ and $S_{1}$ rotational potential energy surfaces is nearly unaffected by substitution of the phenyl groups, unless the substituents are bulky enough to cause substantial interactions. ${ }^{20,51}$ This is demonstrated by the facts that both compounds 64 and 65 still keep the features of rotational profiles of $\mathbf{6 3}$ (i.e., Fig. 8b), but the energy surfaces for the all-pentiptycene derivative $\mathbf{4 2}$ have

multiple minima in both $\mathrm{S}_{0}$ and $\mathrm{S}_{1}$ (Fig. 8a). ${ }^{20}$ As a result, the excited-state conformational relaxation from the twisted to the coplanar conformation is inhibited for $\mathbf{4 2}$ at low temperatures and the conformation effects can be thus evaluated. The results showed that twisting of the phenyl rings leads to blue-shifted absorption and fluorescence spectra, consistent with the theoretical prediction, and increased fluorescence quantum yield and lifetimes. Similar behavior was also observed for the fourring system $\mathbf{4 3}$.

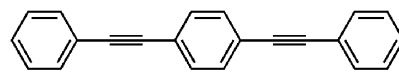

63-coplanar

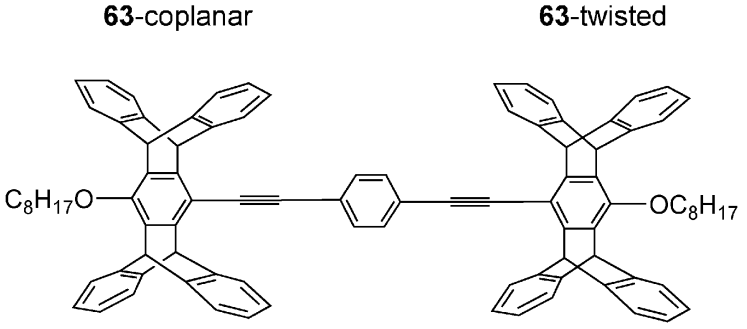

64

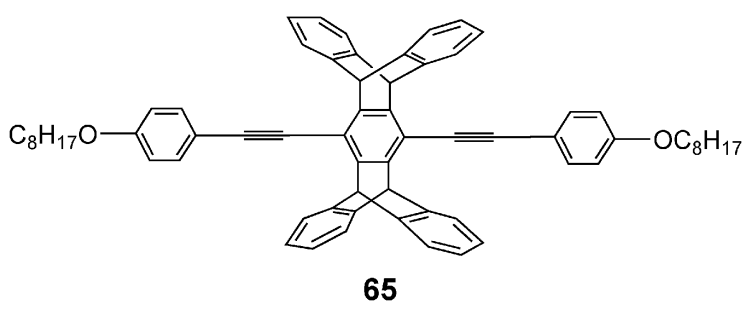

Although the conjugated backbone of PE systems is rather rigid, the backbone of a long PE polymer (i.e., PPEs) in isotropic solutions might be disordered (e.g., bent or coiled), which might reduce the efficiency of exciton movement within the conjugated backbone. In this context, Swager et al. have combined the structural features of pentiptycene and nematic liquid crystals (LCs) to enhance the conformational order of PPEs. ${ }^{52}$ This relies on the concept of 'minimization of free volume', ${ }^{53}$ corresponding to the occupation of the convex space defined by the pentiptycene groups by the highly organized LC molecules. As evidenced by a substantial increase of intrachain energy transfer from the polymer chain to the terminal energy acceptors for polymer $\mathbf{6 6}$ in nematic LC vs. isotropic solution, the effective conjugation length is larger in the former solution.

\section{(e) Function as a rotary component in molecular machines}

A molecular machine is a molecule designed to perform a computation, a motion, or a measurement in response to some data inputs or orders provided by an operator. Therefore, the ability to control molecular motion is the first step toward the

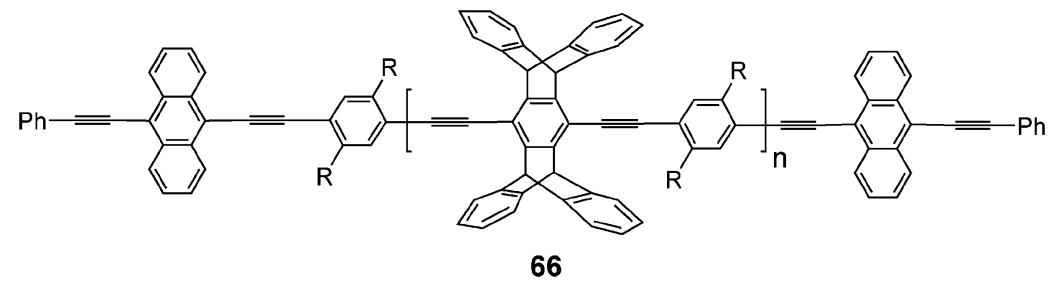




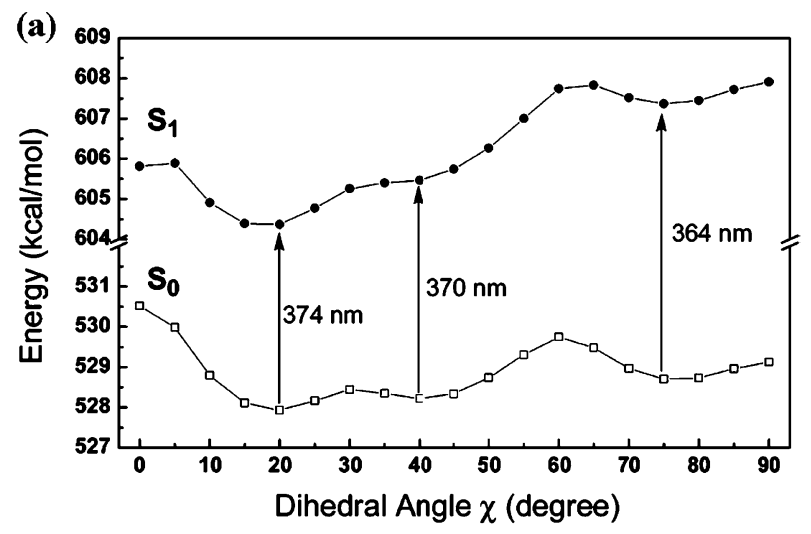

rotation in the absence of $\mathrm{Cu}^{+}$, but the rotation was restricted upon complexation with $\mathrm{Cu}^{+}$. The free rotation of the pentiptycene group can be restored by decomplexation with cyanide ions.

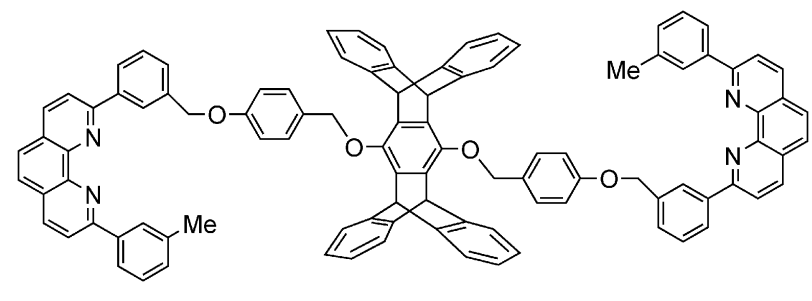

67

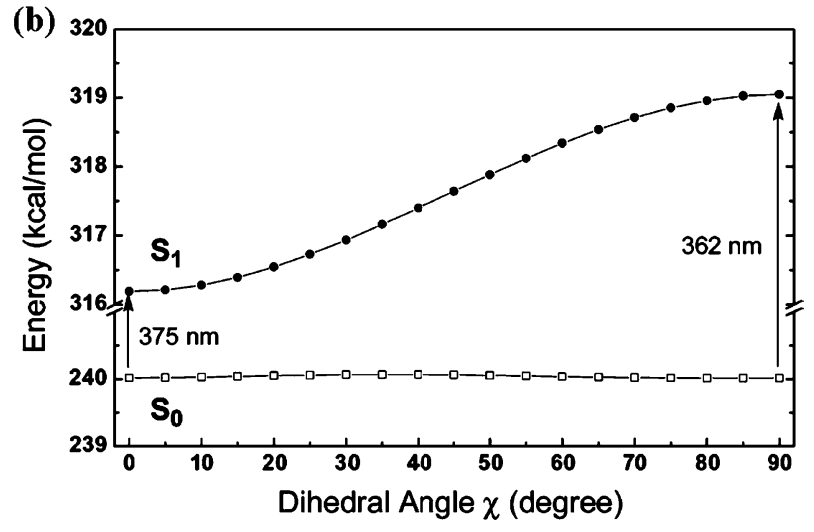

Fig. 8 Rotational potential of (a) 42 and (b) 65 in the ground $\left(S_{0}\right)$ and the lowest excited $\left(\mathrm{S}_{1}\right)$ state derived from AM1 and ZINDO algorithm. To expedite the calculations, the octyl groups were replaced by methyl groups. Wavelengths for vertical transitions at selected dihedral angles are indicated with labeled arrows. Reproduced with permission from $J$. Am. Chem. Soc., 2006, 128, 14109. ${ }^{20}$ (C) 2006, American Chemical Society.

development of molecular machines or molecular computers. Although many prototype examples have shown significant progress in controlling the motion of molecules, building molecular machines mimicking the molecular motors present in biological systems (e.g., the kinase linear motor and the ATP-ase rotary motor $)^{54}$ remains a challenging task. Several of the prototype artificial molecular rotors reported in the literature ${ }^{55}$ adopted triptycene as the rotary component (e.g., 7). ${ }^{6,56}$ If triptycene is considered as a three-bladed molecular rotor around the axis connecting the two bridgehead carbons, pentiptycene represents a four-bladed molecular rotor around the axis along the central ring. Cozzi et al. have reported one such example, called a molecular 'gate' (compound 67), where the internal rotation of the pentiptycene group can be gated by external chemical stimuli. ${ }^{57}$ As schematically depicted in Fig. 9, the pentiptycene group in $\mathbf{6 7}$ can undergo free internal
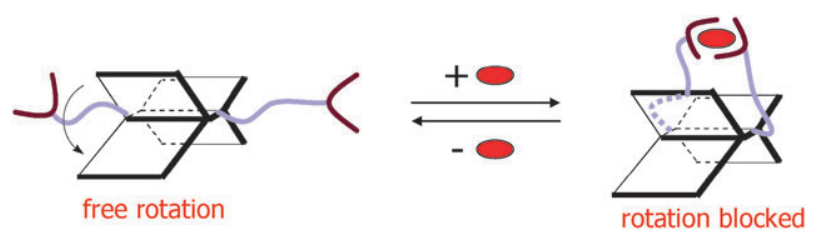

Fig. 9 Schematic representation of the function of the metal ioncontrolled molecular gate $\mathbf{6 7}$.

\section{Conclusions and outlook}

The pentiptycene scaffold differs from triptycene in having a central ring that is 'shielded' by the protruding peripheral phenyl rings. While such a feature continues to find unique applications in contemporary chemistry, the progress of pentiptycene chemistry depends on the availability of the centralring functionalized pentiptycene building blocks. Our experience has shown that the outcome of functional-group transformations for the central ring is very sensitive to the reaction conditions. In other words, a small variation of the reaction conditions such as solvent, temperature, or reaction time could lead to the complete failure or success of the reaction. Although several central-ring functionalized building blocks are currently available, more new pentiptycene building blocks are desired. For example, pentiptycene dihalides would be useful for preparing all-pentiptycene PE polymer and other $\pi$-conjugated derivatives, but they have not yet been successfully prepared. Certainly, application of the pentiptycene scaffold should not be limited to the central-ring substituted species, since the $\mathrm{H}$-shaped scaffold is inherently different from the Y-shaped scaffold of triptycene. We can envision that as the synthetic barrier is overcome, more diversified applications of the pentiptycene scaffold will be demonstrated. Regarding the close structural relationship between pentiptycene and larger iptycenes, the synthetic methods and application concepts developed for pentiptycene might also inspire more new chemistry for larger iptycenes.

\section{Acknowledgements}

We thank the National Science Council of Taiwan and Academia Sinica for financial support.

\section{Notes and references}

1 P. D. Bartlett, M. J. Ryan and S. G. Cohen, J. Am. Chem. Soc., 1942, 64, 2649.

2 H. Hart, S. Shamouilian and Y. Takehira, J. Org. Chem., 1981, 46, 4427.

3 (a) G. Witing and R. Ludwig, Angew. Chem., 1956, 68, 40; (b) C. F. Huebner, R. T. Puckett, M. Brzechfta and S. L. Schwartz, Tetrahedron Lett., 1970, 11, 359; (c) P. Venugopalan, H.-B. Bürgi, N. L. Frank, K. K. Baldridge and J. S. Siegel, Tetrahedron Lett., 1995, 36, 2419.

4 G. Yamamoto, Chem. Lett., 1990, 19, 1373. 
5 B. W. Gung, X. Xue and H. J. Reich, J. Org. Chem., 2005, 70, 3641.

6 T. R. Kelly, Acc. Chem. Res., 2001, 34, 514.

7 S. Norvez, J. Org. Chem., 1993, 58, 2414.

8 D. Gelman, O. Grossman and C. Azerraf, Organometallics, 2006, 25, 375.

9 (a) J.-S. Yang, C.-P. Liu, B.-C. Lin, C.-W. Tu and G.-H. Lee, J. Org. Chem., 2002, 67, 7343; (b) J. H. Chong and M. J. MacLachlan, Inorg. Chem., 2006, 45, 1442.

10 E. Liba, K. Hirai, H. Tomioka and Y. Yoshioka, J. Am. Chem. Soc., 2002, 124, 14308.

11 C. E. Godinez, G. Zepeda and M. A. Garcia-Garibay, J. Am. Chem. Soc., 2002, 124, 4701.

12 J.-S. Yang and J.-L. Yan, J. Chin. Chem. Soc., 2006, 53, 1509.

13 (a) K. Shahlai and H. Hart, J. Org. Chem., 1991, 56, 6905; (b) H. Hart, Pure Appl. Chem., 1993, 65, 27.

14 V. R. Skvarchenko and V. K. Shalaev, Dokl. Akad. Nauk SSSR, Ser. Khim., 1974, 216, 110.

15 V. E. Williams and T. M. Swager, Macromolecules, 2000, 33, 4069.

16 E. Clar, Ber. Dtsch. Chem. Ges., 1931, 64, 1676.

17 W. Theilacker, U. Berger-Brose and K.-H. Beyer, Chem. Ber., 1960, 93, 1658.

18 (a) J.-S. Yang and T. M. Swager, J. Am. Chem. Soc., 1998, 120, 5321; (b) J.-S. Yang and T. M. Swager, J. Am. Chem. Soc., 1998, $120,11864$.

19 X.-Z. Zhu and C.-F. Chen, J. Org. Chem., 2005, 70, 917.

20 J.-S. Yang, J.-L. Yan, C.-Y. Hwang, S.-Y. Chiou, K.-L. Liau, H.H. G. Tsai, G.-H. Lee and S.-M. Peng, J. Am. Chem. Soc., 2006, 128, 14109.

21 J.-S. Yang and C.-W. Ko, J. Org. Chem., 2006, 71, 844.

22 (a) J. I. G. Cadogan, D. A. Roy and D. M. Smith, J. Chem. Soc. C, 1966, 1249; (b) A. L. J. Beckwith and R. O. C. Norman, J. Chem. Soc. B, 1969, 403; (c) J. I. G. Cadogan and G. A. Molina, J. Chem. Soc., Perkin Trans. 1, 1973, 541.

23 L. Yin and J. Liebscher, Chem. Rev., 2007, 107, 133.

24 J.-S. Yang and J.-L. Yan, unpublished results.

25 Handbook of Physical Properties of Organic Chemicals, ed. P. H. Howard and W. M. Meylan, CRC Press, Boca Raton, 1997.

26 Handbook Series in Organic Electrochemistry, ed. L. Meites and P. Zuman, CRC Press, Boca Raton, 1978, vol. 1.

27 (a) C. Cumming, C. Aker, M. Fisher, M. Fox, M. laGrone, D. Reust, M. Rockley, T. M. Swager, E. Towers and V. Williams, IEEE Trans. Geosci. Remote Sensing, 2001, 39, 1119; (b) A. Rose, Z. Zhu, C. F. Madigan, T. M. Swager and V. Bulović, Proc. SPIE-Int. Soc. Opt. Eng., 2006, 6333, 63330Y.

28 S. W. Thomas III, G. D. Joly and T. M. Swager, Chem. Rev., 2007, 107, 1339.

29 J. P. Amara and T. M. Swager, Macromolecules, 2005, 38, 9091.

30 S. W. Thomas III and T. M. Swager, Adv. Mater., 2006, 18, 1047.

31 S. Yamaguchi and T. M. Swager, J. Am. Chem. Soc., 2001, 123, 12087.

32 S. Zahn and T. M. Swager, Angew. Chem., Int. Ed., 2002, 41, 4225.

33 D. Zhao and T. M. Swager, Macromolecules, 2005, 38, 9377.

34 X. Zhao, T. Cardolaccia, R. T. Farley, K. A. Abboud and K. S. Schanze, Inorg. Chem., 2005, 44, 2619.

35 (a) B. H. Hong, J. Y. Lee, C.-W. Lee, J. C. Kim, S. C. Bae and K. S. Kim, J. Am. Chem. Soc., 2001, 123, 10748; (b) S. Hecht and A. Khan, Angew. Chem., Int. Ed., 2003, 42, 6021.

36 (a) M. S. Vollmer, T. D. Clark, C. Steinem and M. R. Ghadiri, Angew. Chem., Int. Ed., 1999, 38, 1598; (b) W. Zhang and J. S. Moore, Angew. Chem., Int. Ed., 2006, 45, 4416.

37 C. Zhang and C.-F. Chen, J. Org. Chem., 2007, 72, 3880.
38 S. A. Miller, E. Kim, D. H. Gray and D. L. Gin, Angew. Chem., Int. Ed., 1999, 38, 3021.

39 J.-S. Yang, C.-P. Liu and G.-H. Lee, Tetrahedron Lett., 2000, 41, 7911.

40 T. M. Long and T. M. Swager, J. Am. Chem. Soc., 2003, 125, 14113.

41 R. M. A. Azzam and N. M. Bashara, Ellipsometry and Polarized Light, Elsevier, Amsterdam, 1977.

42 J.-S. Yang, C.-S. Lin and C.-Y. Hwang, Org. Lett., 2001, 3, 889.

43 A. P. de Silva, H. Q. N. Gunaratne, T. Gunnlaugsson, A. J. M. Huxley, C. P. McCoy, J. T. Rademacher and T. E. Rice, Chem. Rev., 1997, 97, 1515.

44 H. J. Kim, J. H. Bok, J. Vicens, I.-H. Suh, J. Ko and J. S. Kim, Tetrahedron Lett., 2005, 46, 8765.

45 (a) J. M. Tour, L. Jones, D. L. Pearson, J. J. S. Lamba, T. P. Burgin, G. M. Whitesides, D. L. Allara, A. N. Parikh and S. V. Atre, J. Am. Chem. Soc., 1995, 117, 9529; (b) P. Kohli, K. K. Taylor, J. J. Harris and G. J. Blanchard, J. Am. Chem. Soc., 1998, 120, 11962; (c) J. M. Tour, L. Cheng, D. P. Nackashi, Y. Yao, A. K. Flatt, S. K. S. Angelo, T. E. Mallouk and P. D. Franzon, J. Am. Chem. Soc., 2003, 125, 13279; (d) K. H. A. Lau, C. Huang, N. Yakovlev, Z. K. Chen and S. J. O'Shea, Langmuir, 2006, 22, 2968.

46 (a) R. P. Andres, J. D. Bielefeld, J. I. Henderson, D. B. Janes, V. R. Kolagunta, C. P. Kubiak, W. J. Mahoney and R. G. Osifchin, Science, 1996, 273, 1690; (b) R. Resch, C. Baur, A. Bugacov, B. E. Koel, P. M. Echternach, A. Madhukar, N. Montoya, A. A. G. Requicha and P. Will, J. Phys. Chem. B, 1999, 103, 3647-3650; (c) G. K. Ramachandran, T. J. Hopson, A. M. Rawlett, L. A. Nagahara, A. Primak and S. M. Lindsay, Science, 2003, 300, 1413; (d) K. Walzer, E. Marx, N. C. Greenham, R. J. Less, P. R. Raithby and K. Stokbro, J. Am. Chem. Soc., 2004, 126, 1229; (e) Y. Tai, A. Shaporenko, H. Noda, M. Grunze and M. Zharnikov, Adv. Mater., 2005, 17, 1745.

47 J.-S. Yang, C.-C. Lee, S.-L. Yau, C.-C. Chang, C.-C. Lee and J.-M. Leu, J. Org. Chem., 2000, 65, 871.

48 (a) M. Levitus, K. Schmieder, H. Ricks, K. D. Schimizu, U. H. F. Bunz and M. A. Garcia-Garibay, J. Am. Chem. Soc., 2001, 123, 4259; (b) S. J. Greaves, E. L. Flynn, E. L. Futcher, E. Wrede, D. P. Lydon, P. J. Low, S. R. Rutter and A. Beeby, J. Phys. Chem. A, 2006, 110, 2114; (c) P. V. James, P. K. Sudeep, C. H. Suresh and K. G. Thomas, J. Phys. Chem. A, 2006, 110, 4329.

49 M. I. Sluch, A. Godt, U. H. F. Bunz and M. A. Berg, J. Am. Chem. Soc., 2001, 123, 6447.

50 L. G. Wade, Jr, Organic Chemistry, Pearson Prentice Hall, Upper Saddle River, 6th edn, 2006, p. 97.

51 B. C. Englert, M. D. Smith, K. I. Hardcastle and U. H. F. Bunz, Macromolecules, 2004, 37, 8212.

52 E. E. Nesterov, Z. Zhu and T. M. Swager, J. Am. Chem. Soc., 2005, 127, 10083.

53 (a) T. M. Long and T. M. Swager, Adv. Mater., 2001, 13, 601; (b) T. M. Long and T. M. Swager, J. Am. Chem. Soc., 2002, 124, 3826.

54 (a) R. D. Vale and R. A. Milligan, Science, 2000, 288, 88; (b) Molecular Motors, ed. M. Schliwa, Wiley-VCH, Weinheim, 2003; (c) R. B. Vallee and P. Höök, Nature, 2003, 421, 701; (d) M. J. A. Tyreman and J. E. Molloy, IEEE Proc.: Nanobiotechnol., 2003, 150, 95; (e) M. Schliwa and G. Woehlke, Nature, 2003, 422, 759.

55 G. S. Kottas, L. I. Clarke, D. Horinek and J. Michl, Chem. Rev., 2005, 105, 1281.

56 T. R. Kelly, M. C. Bowyer, K. V. Bhaska, D. Bebbington, A. Garcia, F. Lang, M. H. Kim and M. P. Jette, J. Am. Chem. Soc., 1994, 116, 3657.

57 R. Annunziata, M. Benaglia, M. Cinquini, L. Raimondi and F. Cozzi, J. Phys. Org. Chem., 2004, 17, 749. 